\title{
STRONG CONVERGENCE OF PROJECTED REFLECTED GRADIENT METHODS FOR VARIATIONAL INEQUALITIES
}

\author{
PAUL-EMILE MAINGÉ \\ University of Antilles, Martinique, French West Indies \\ E-mail: Paul-Emile.Mainge@martinique.univ-ag.fr
}

\begin{abstract}
The purpose of this work is to revisit the numerical approach to classical variational inequality problems, with monotone and Lipschitz continuous mapping, by means of a regularized dynamical method. A main feature of the method is that it formally requires only one projection step onto the feasible set and only one evaluation of the involved mapping (at each iteration), combined with some viscosity-like regularization process. A strong convergence theorem is established in a general setting that allows the use of varying step-sizes without any requirement of additional projections. We also point out that the considered method in absence of regularization does not generate a Fejer-monotone monotone sequence. So a new analysis is developed for this purpose.

Key Words and Phrases: Variational inequality, monotone operator, dynamical-type method, strong convergence, regularization process, viscosity method.
\end{abstract}

2010 Mathematics Subject Classification: 47J20, 90C25, 90C30, 90C52.

\section{REFERENCES}

[1] D.P. Bertsekas, On the Goldstein-Levitin-Polyak gradient projection method, IEEE Trans. Automatic Control, 21(1976), no. 2, 174-184.

[2] D.P. Bertsekas, E.M. Gafni, Projection methods for variational inequalities with applications to the traffic assignment problem, Math. Prog. Study, 17(1982), 139-159.

[3] H. Brezis, Opérateurs maximaux monotones, North Holland Mathematics Studies, 5(1973).

[4] R.S. Burachik, J.O. Lopes, B.S. Svaiter, An outer approximation method for the variational inequality problem, SIAM J. Control Optim., 43(2005), no. 6, 2071-2088.

[5] Y. Censor, A. Gibali, S. Reich, The subgradient extragradient method for solving variational inequalities in Hibert spaces, J. Optim. Theory Appl., 148(2011), 318-355.

[6] B. Halpern, Fixed points of nonexpanding maps, Bull. Amer. Math. Soc., 73(1967), 957-961.

[7] H. Iiduka, W. Takahashi, M. Toyoda, Approximations of solutions of variational inequalities for monotone mappings, Pan American Mathematical Journal, 14(2004), 49-61.

[8] S. Itoh, W. Takahashi, The common fixed point theory of singlevalued mappings and multivalued mappings, Pacific J. Math., 79(1978), no. 2, 493-508.

[9] A.N. Iusem, An iterative algorithm for the variational inequality problem, Math. Applied Comp., 13(1994), 103-114.

[10] A.N. Iusem, L.R. Pérez, An extragradient-type algorithm for nonsmooth variational inequalities, Optimization, 48(2000), 309-332.

[11] A.N. Iusem, B.F. Svaiter, A variant of Korpelevich's method for variational inequalities with a new search strategy, Optimization, 42(1997), 309-321. 
[12] E.N. Khobotov, Modification of the extragradient method for solving variational inequalities and certain optimization problems, USSR Comp. Math. Phys., 27(1987), 120-127.

[13] G.M. Korpelevich, The extragradient method for finding saddle points and other problems, Matecon, 12(1976), 747-756.

[14] P.E. Maingé, Strong convergence of projected subgradient methods for nonsmooth and nonstrictly convex minimization, Set-Valued Analysis, 16(2008), no. 7-8, 899-912.

[15] P.E. Maingé, A hybrid extragradient-viscosity method for monotone operators and fixed point problems, SIAM J. Control Optim., 47(2008), no. 3, 1499-1515.

[16] P.E. Maingé, M.L. Gobinddass, Convergence of one-step projected gradient methods for variational inequalities, Internal Report, Université des Antilles, 2015.

[17] P.E. Maingé, S. Maruster, Convergence in norm of Kranoselski-Mann iterations for fixed points of demicontractive mappings, Applied Mathematics and Computation, 217(2011), no. 24, 98649874 .

[18] Yu. Malitski, Projected reflected gradient method for variational inequalities, SIAM J. Optim., $\mathbf{2 5}(2015)$, no. 1, 502-520.

[19] Yu. Malitsky, V.V Semenov, An extragradient algorithm for monotone variational inequalities, Cybernetics and Systems Anal., 50(2014), 271-277.

[20] P. Marcotte, Applications of Khobotov's algorithm to variational and network equlibrium problems, Inform. Systems Oper. Res., 29(1991), 258-270.

[21] M.A. Noor, Modified projection method for pseudomonotone variational inequlities, Applied Mathematics Letters, 15(2002), 315-320.

[22] M.V. Solodov, P. Tseng, Modified projection methods for monotone variational inequalities, SIAM J. Control Optim., 34(1996), no. 5, 1814-1834.

[23] M.V. Solodov, B. F. Svaiter, A new projection method for variational inequality problems, SIAM J. Control Optim., 37(1999), 765-776.

[24] G. Stampacchia, Formes bilinéaires coercitives sur les ensembles convexes, C.R.A.S., Paris, 258(1964), 4413-4416.

[25] D. Sun, An iterative method for solving variational inquality problems and complementarity problems, Numer. Math., J. Chin. Univ., 16(1994), 145-153.

[26] D. Sun, A class of iterative methods for solving nonlinear projection equations, J. Optim. Theory and Appl., 91(1996), 123-140.

[27] W. Takahashi, Convex Analysis and Approximation of Fixed Points, Yokohama Publishers, Yokohama, Japan, 2000.

[28] W. Takahashi, Nonlinear Functional Analysis, Yokohama Publishers, Yokohama, Japan, 2000.

[29] P. Tseng, On linear convergence of iterative methods for the variational inequality problem, J. Comp. Appl. Math., 60(1995), 237-252.

[30] P. Tseng, A modified forward-backward splitting method for maximal monotone mappings, SIAM J. Control Optim., 38(2000), 431-446.

[31] N. Xiu, J. Zhang, Some recent advances in projection-type mathods for variational inequalities, J. Comp. Applied Math., 152(2003), 559-585.

Received: March 24, 2016; Accepted: May 27, 2016. 
